\title{
Extended-release divalproex in bipolar and other psychiatric disorders:A comprehensive review
}

\author{
Steven C Stoner' \\ Megan M Dahmen² \\ 'Northwest Missouri Psychiatric \\ Rehabilitation Center, Department of \\ Pharmacy, St. Joseph, Missouri, USA; \\ ${ }^{2}$ University of Missouri-Kansas \\ City School of Pharmacy, Division \\ of Pharmacy Practice, Kansas City, \\ Missouri, USA
}

\begin{abstract}
Bipolar disorder can be a devastating disease state for individuals with the disease and also for family members. Proper recognition and treatment is vital to the successful management of this disease state. Through increased community and practitioner awareness, along with efforts to increase awareness for proper assessment, the rate of diagnosed bipolar disorder is increasing. Recent years have brought about the introduction of several new medications with approved indications for the treatment of bipolar disorder. In addition to new agents, traditional mood stabilizing medications have also been released in different formulations to better enhance tolerability without jeopardizing efficacy. One particular product is extended-release divalproex sodium. In the following article, we review the clinical presentation of bipolar disorder, its epidemiology, and the pharmacokinetics and mechanism of action for divalproex. In addition, we specifically review the role of extended-release divalproex in bipolar disorder through a critical analysis of the currently available published primary literature.
\end{abstract}

Keywords: extended-release divalproex, divalproex, bipolar disorder, mania, depression

\section{Bipolar disorder}

Bipolar disorder is a psychiatric disease state manifesting as two different mood extremes, mania and depression. Manic symptoms often include hyperactivity, hypertalkativeness, decreased need for sleep, grandiosity, increased risk taking, and being easily distracted (APA 2000). Depression symptoms typically consist of a depressed mood, decreased energy, feelings of guilt, hopelessness, helplessness, crying, and even suicidal ideations (APA 2000).

Symptoms of bipolar disorder typically present during late adolescence between the ages of 15 and 19 years, however it is not uncommon for proper diagnosis to be delayed for 5-10 years (Bowden et al 2002). Bipolar I disorder is estimated to be prevalent in $1 \%$ of the US population, however recent findings from a large-scale survey suggest an adjusted prevalence rate near 3.7\% (Bowden et al 2002; Hirschfeld, Calabrese et al 2003). Additionally, it has been found through survey that there is often a gap of up to 10 years between the first visit and subsequent proper diagnosis, with the majority either not being diagnosed at all or inappropriately diagnosed with unipolar depression (Hirschfeld, Calabrese et al 2003; Hirschfeld, Lewis et al 2003). Identification of which type of bipolar disorder is present is complicated by the fact that both bipolar I and bipolar II patients spend more time symptomatic in the depressed phase than the manic or hypomanic states (Judd et al 2002). This is significant when considering the potential risk of switching a bipolar patient from a depressed state to manic state with antidepressant therapy. Contrary to this is that failure to address a depressive episode of bipolar disorder presents a dramatic increase in suicide risk. Additional things to consider when treating a patient with bipolar disorder are the high rates of concurrent substance abuse and anxiety disorders (Bowden et al 2002; McElroy 2004). 


\section{Valproate mechanism}

The mechanism by which valproate exerts its therapeutic effect is not well understood. Several hypotheses have been proposed concerning the mechanism of action in epilepsy and bipolar disorder. The most well studied and understood mechanism of valproate is its ability to potentiate or mimic the effects of the inhibitory neurotransmitter, gammaaminobutyric acid (GABA) (Loscher 2002; Casey et al 2003; Salloum et al 2005). Indirectly, this potentiation of GABA has been hypothesized to produce inhibitory effects on central dopamine (Casey et al 2002; Loscher 2002). Some of the other and less well understood mechanisms involve the inhibition of neuronal excitability and a resultant antikindling effect (Loscher 2002). One specific area of study has focused on the inhibition of protein kinase $\mathrm{C}$ epsilon (PKC-epsilon) (Brunello 2004; Toth 2005). PKC-epsilon has been linked to the stimulation of intracellular calcium release and an increase in cortical excitation and instability. Valproate has also exhibited effects producing the blockade of voltage-dependent sodium channels (Loscher 2002; Owens and Nemeroff 2003). Another proposed mechanism, though controversial, is one likening valproate to lithium as a potential inhibitor of inositol synthesis through inhibition of myo-inositol-1phosphate (MIP) (Harwood and Agam 2003; Shaltiel et al 2004; Harwood 2005). It is not well understood if valproate inhibits MIP directly, but it has been shown to deplete inositol (Harwood and Agam 2003; Shaltiel et al 2004; Harwood 2005).

\section{Divalproex pharmacology Delayed-release divalproex}

Delayed-release divalproex (DR) is an enteric-coated compound consisting of sodium valproate and valproic acid in a 1:1 molar ratio (Abbott Laboratories 2006). Divalproex is metabolized in the liver, primarily via glucuronidation to active metabolites, with the major active metabolite being Trans-2-en-valproate (Loscher 2002). The estimated half-life of divalproex ranges from 9 to 16 hours (Abbott Laboratories 2006). The usual dosing regimen for DR is on a two or three times daily schedule, often with the larger dose given at bedtime. The therapeutic range for divalproex sodium in acute mania according to primary literature suggests improvement is greatest at concentrations above $50 \mu \mathrm{g} / \mathrm{mL}$ and that adverse effects increase significantly at concentrations above $125 \mu \mathrm{g} / \mathrm{mL}$ (Bowden et al 2002). The more common side effects of DR are transient nausea (31\%), asthenia (20\%), somnolence (17\%), dyspepsia (13\%), dizziness (12\%), diarrhea (12\%), vomiting (11\%), and tremor
(9\%) (Abbott Laboratories 2006). Some long-term side effects that have been associated with DR use are alopecia and weight gain. Therapeutic drug monitoring for valproic acid or any formulation of divalproex requires periodic monitoring of liver enzymes as serious liver toxicity has been reported, especially with use in children under the age of two and in patients receiving multiple antiepileptic medications. Valproic acid/divalproex have also been shown to produce a dose-related thrombocytopenia, thus periodic monitoring of platelets is also suggested. The primary advantage of the DR formulation over immediate release valproic acid (IR) is the enteric coating which helps reduce the incidence of gastrointestinal complaints. Prevalence of hepatic enzyme elevation, tremor, ataxia, increased appetite, weight gain, and alopecia have not been shown to be substantially different in clinical trials between DR and IR preparations.

\section{Extended-release divalproex}

The newest formulation of divalproex is in the form of an extended-release tablet, Depakote $E^{\circledR}(E R)$, which provides a once-daily administration option for the treatment of acute manic or mixed episodes of bipolar disorder, independent of the presence of psychotic features (Abbott Laboratories 2006). The ER formulation uses a hydrophilic polymer matrix controlled-release tablet system to provide controlled continued release of medication. After oral administration and entry into the stomach, the outer coating of the tablet dissolves and exposes the polymer matrix. The outer layer of the matrix becomes hydrated and forms a gel layer from which drug is released. In addition to bipolar disorder, ER is also approved for the prophylactic management of migraine headaches in adults, as well as monotherapy and adjunctive therapy in adults and children 10 years of age and older with complex partial seizures, adults and children 10 years of age or older with simple and complex absence seizures, and adults and children 10 years of age and older with multiple seizure types including absence seizures (Abbott Laboratories 2006).

Comparative studies have shown that DR and ER are not bioequivalent products. The two primary kinetic differences are that the ER preparation results in an average bioavailability of $81 \%-89 \%$ relative to DR and ER has produces a $10 \%-20 \%$ lower fluctuation in peak serum concentration as compared to DR (Abbott Laboratories 2006). These findings suggest that when converting patients from DR to ER that the ER dose may need to be increased between $8 \%$ and $20 \%$ to produce an equivalent serum concentration.

Further evidence for pharmacokinetic differences were supported in a study using a healthy adult population and 
comparing the bioavailability of unequal doses of DR and ER (Dutta et al 2002). The results from this study determined that daily doses of ER dosed $14 \%$ and $20 \%$ higher than DR (1000 mg/day ER vs $875 \mathrm{mg} /$ day DR and $1500 \mathrm{mg}$ /day ER vs $1250 \mathrm{mg}$ /day DR) produced equivalent serum concentrations as determined by area-under-the-curve (AUC) (Dutta et al 2002). The ER preparation resulted in a lower $C_{\max }$ and a higher $\mathrm{C}_{\text {min }}$ than corresponding DR doses. Peak-to-trough fluctuations were $42 \%-48 \%$ lower for the ER preparation (Dutta et al 2002). This study also showed that the increase in dose required with the ER dosage form was well tolerated (Dutta et al 2002). While evidence is increasing, there continues to be a relative paucity of information available describing the use of ER in treating mood related symptoms within the psychiatric population.

\section{Role of divalproex in bipolar disorder}

There have been a number of recent additions to the list of approved medications for the treatment of bipolar disorder (see Table 1). Despite these new advancements in drug delivery and efficacy for the treatment of bipolar disorder, DR continues to be a highly utilized mood stabilizer for the treatment of acute mania (Abbott Laboratories 2006). In many instances, bipolar disorder treatment guidelines recommend valproate as a preferred agent, with DR usually being the suggested formulation of valproate/valproic acid (divalproex) due to the presumed improved tolerability (Zarate et al 1999; Bowden et al 2002; Keck et al 2004; Suppes et al 2005). The disease states where evidence based guidelines support the use of valproate as a first-line choice include: acute manic exacerbations, euphoric mania, dysphoric or mixed mania, and in patients being treated for rapid cycling bipolar disorder (see Table 2) (Bowden et al 2002; Keck et al 2004; Suppes et al 2005). Valproate is also considered an appropriate agent for maintenance therapy, though it lacks the FDA maintenance indication (Taylor and Goodwin 2006). Other FDA approved indications for DR include the treatment of complex partial, simple absence, and complex absence seizures in addition to prophylaxis of migraine headaches (Abbott Laboratories 2006). DR is not FDA approved for aggression, though it is routinely used as monotherapy and is considered appropriate adjunct therapy to reduce hostility associated with schizophrenia (Citrome, Casey et al 2004; Lehman et al 2004).

\section{Clinical trials - efficacy}

In order to identify published, primary literature studying the ER formulation in bipolar disorder we conducted an Ovid Medline search. Our search terms included bipolar disorder, mania, depression, extended-release divalproex, delayed-release divalproex, divalproex, and schizophrenia. We did not include any information that was not published in primary literature form so any "Data on File" with Abbott Laboratories that is not published is not included in this review. Our search yielded a small number of clinical trials reporting on the use of extended-release divalproex in bipolar disorder. Three of the trials are open-label with a study enrollment ranging from 10 to 55 patients. The other three data sets included were published as "Letters to the Editor," but were included for completeness of discussion. One additional study was included that examined the use

Table I FDA approved medications for the treatment of bipolar disorder and their approved indications

\begin{tabular}{|c|c|c|c|c|c|}
\hline \multicolumn{6}{|c|}{ FDA approved agents for management of bipolar disorder as of December 2006} \\
\hline & Mania & $\begin{array}{l}\text { Mixed } \\
\text { episodes }\end{array}$ & $\begin{array}{l}\text { With or without } \\
\text { psychotic features }\end{array}$ & Maintenance & $\begin{array}{l}\text { Bipolar } \\
\text { depression }\end{array}$ \\
\hline 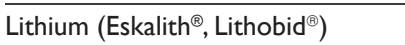 & $\mathrm{x}$ & & & $\mathrm{x}$ & \\
\hline Valproate (Depakote ${ }^{\circledR}$ ) & $\mathrm{x}$ & & & & \\
\hline Divalproex ER (Depakote ER ${ }^{\circledR}$ ) & $x$ & $x$ & $x$ & & \\
\hline Carbamazepine ER (Equetro ${ }^{\circledR}$ ) & $\mathrm{x}$ & $\mathrm{x}$ & & & \\
\hline Chlorpromazine (Thorazine ${ }^{\circledR}$ ) & $x$ & & & & \\
\hline Olanzapine $\left(Z_{y p r e x a}{ }^{\oplus}\right)$ & $x$ & $x$ & $x$ & $x$ & \\
\hline Risperidone $\left(\right.$ Risperdal ${ }^{\circledR}$ ) & $\mathrm{x}$ & $x$ & $x$ & & \\
\hline Quetiapine (Seroquel ${ }^{\circledR}$ ) & $x$ & & & & $\mathrm{x}$ \\
\hline Ziprasidone (Geodon ${ }^{\circledR}$ ) & $x$ & $x$ & $x$ & & \\
\hline Aripiprazole $\left(\right.$ Abilify $\left.{ }^{\circledR}\right)$ & $x$ & $x$ & $x$ & $x$ & \\
\hline Lamotrigine $\left(\right.$ Lamictal $\left.^{\circledR}\right)$ & & & & $x$ & \\
\hline Olanzapine/Fluoxetine $\left(\right.$ Symbyax $\left.^{\circledR}\right)$ & & & & & $x$ \\
\hline
\end{tabular}

References: Bowden et al 2002; GlaxoSmithKline 2003, 2006; Keck et al 2004; Shire US Incorporated 2004; Pfizer 2005; Suppes et al 2005; Abbott Laboratories 2006; AstraZeneca 2006; Bristol-Myers Squibb 2006; Eli Lilly and Company 2006; Janssen 2006; Solvay Pharmaceuticals 2006. 
Table 2 Suggested first-line treatment strategies per available guidelines

\begin{tabular}{|c|c|c|c|c|c|c|c|}
\hline \multicolumn{8}{|c|}{ Guidelines for the treatment of bipolar disorder } \\
\hline & $\begin{array}{l}\text { Non- } \\
\text { psychotic } \\
\text { mania }\end{array}$ & $\begin{array}{l}\text { Mixed } \\
\text { mania }\end{array}$ & $\begin{array}{l}\text { Dysphoric } \\
\text { mania }\end{array}$ & $\begin{array}{l}\text { Mania with } \\
\text { a history of } \\
\text { rapid cycling }\end{array}$ & $\begin{array}{l}\text { Euphoric } \\
\text { mania }\end{array}$ & $\begin{array}{l}\text { Psychotic } \\
\text { mania }\end{array}$ & $\begin{array}{l}\text { Bipolar } \\
\text { depression }\end{array}$ \\
\hline$\overline{\mathrm{APA}}$ & & $\begin{array}{l}\text { Severe: Li } \\
\text { plus AP OR } \\
\text { VPA plus } \\
\text { AP } \\
\text { Less Severe: } \\
\text { monotherapy } \\
\text { Li,VPA or } \\
\text { AP }\end{array}$ & & Li OR VPA & & & Li OR LAM \\
\hline $\begin{array}{l}\text { Expert } \\
\text { Consensus } \\
2004\end{array}$ & $\begin{array}{l}\text { Combination } \\
\text { MS plus AP } \\
\text { OR } \\
\text { monotherapy } \\
\text { MS }\end{array}$ & $\begin{array}{l}\text { Combo } \\
\text { therapy and } \\
\text { monotherapy } \\
\text { received } \\
\text { equivalent } \\
\text { ratings }\end{array}$ & $\begin{array}{l}\text { Combination } \\
\text { treatment } \\
\text { and } \\
\text { monotherapy } \\
\text { received } \\
\text { equivalent } \\
\text { ratings }\end{array}$ & $\begin{array}{l}\text { Combination } \\
\text { treatment } \\
\text { and } \\
\text { monotherapy } \\
\text { received } \\
\text { equivalent } \\
\text { ratings }\end{array}$ & MS & $\begin{array}{l}\text { MS plus AP } \\
\text { OR } \\
\text { monotherapy } \\
\text { AP }\end{array}$ & $\begin{array}{l}\text { LAM } \\
\text { monotherapy } \\
\text { OR LAM } \\
\text { plus Li for } \\
\text { severe non- } \\
\text { psychotic } \\
\text { depression } \\
\text { with a } \\
\text { history of } \\
\text { AD-induced } \\
\text { mania or } \\
\text { rapid cycling }\end{array}$ \\
\hline TMAP & & $\begin{array}{l}\text { Monotherapy } \\
\text { VPA, ARP, } \\
\text { RIS, ZIP }\end{array}$ & & & $\begin{array}{l}\text { Monotherapy } \\
\text { Li,VPA, } \\
\text { ARP, QTP, } \\
\text { RIS, ZIP }\end{array}$ & & $\begin{array}{l}\text { LAM plus } \\
\text { anti-manic } \\
\text { agent if } \\
\text { recent and/or } \\
\text { severe } \\
\text { history of } \\
\text { mania, all } \\
\text { other } \\
\text { patients } \\
\text { LAM } \\
\text { monotherapy }\end{array}$ \\
\hline
\end{tabular}

Abbreviation: AP,Antipsychotic; MS, Traditional Mood Stabilizer (carbamazepine, divalproex, lithium); Li, Lithium;VPA, Valproate;ARP,Aripiprazole; QTP, Quetiapine; RIS, Risperidone; ZIP, Ziprasidone; LAM, Lamotrigine;AD, Antidepressant. References: Bowden et al 2002; Keck et al 2004; Suppes et al 2005.

of extended-release divalproex for mood stabilization and antipsychotic augmentation in schizophrenia.

The first trial discussed is an open-label, seven day study evaluating the efficacy and safety of converting psychiatric patients from DR to ER (Horne and Cunanan 2003). The majority of participants carried a diagnosis of bipolar disorder or major depression, $36 \%$ and $27 \%$ respectively. Other psychiatric diagnosis included schizophrenia and schizoaffective disorder. A total of 55 patients were included in the conversion, $75 \%$ outpatients and $25 \%$ inpatients hospitalized for acute symptoms. Participants had been treated with DR from 2 days to $>4$ years at doses of 500 to 5,000 $\mathrm{mg} /$ day. Concomitant medications were described and included agents such as antipsychotics, antidepressants, and anxiolytics.
Following baseline measurements of plasma valproic acid concentrations, study participants were switched to ER at a dose equal to their total daily dose of DR. Subsequent therapeutic drug monitoring included assessment of plasma valproic acid concentrations which were obtained 10 to 12 hours after the last dose on study days 3, 5, and 7. Over half the patients in the study (58\%) experienced an increase in valproic acid plasma concentration when switched from DR to ER dosage forms. In all but three cases, plasma concentrations remained within the therapeutic range of $50-125 \mu \mathrm{g} / \mathrm{mL}$. In two of the cases the plasma levels increased following the initiation of the ER dosage form with no signs of toxicity and returned to values within therapeutic range with dosage reduction. In the third case, the patient's serum valproic acid level decreased below the lower limit of normal but increased following dosage titration. 
Efficacy was assessed with the Positive and Negative Syndrome Scale (PANSS) at baseline and endpoint. Upon analysis of the total patient population, a statistically significant improvement was observed in mean PANSS total score, positive subscale and general psychopathology subscale from baseline to endpoint. Mean total PANSS scores at baseline were $71.5 \pm 21.4$ with a mean change of $-4.3 \pm$ 11.1 at endpoint. While a statistical change was appreciated, clinical impact of improvement was most likely small.

Adverse events were assessed with the Udvalg for Kliniske Undersogelser (UKU) Side Effect Rating Scale. Patients reported a decrease in the number and severity of adverse effects at endpoint. Following the cessation of the study, 54 of the 55 participants choose to continue treatment with the ER formulation.

Statistical power was not discussed in the study design. This design characteristic becomes less of an issue for outcome measures in which statistical improvement is observed. Overall, conversion from DR to ER in this inpatient and outpatient psychiatric population was not associated with deterioration in mental status. In addition, a reduction in both the incidence and severity of adverse effects was appreciated with the ER dosing formulation, most likely thought to be the result of lower peak concentrations.

A second published, open-label study highlighted the conversion of DR to ER in ten subjects over a four-week time period (Stoner et al 2004). Subjects were deemed eligible if they had been on DR at least 8 weeks and were considered "stable" in the two weeks preceding study enrollment. Subjects were also required to be experiencing two "mild" adverse events or one "moderate" adverse event that was considered a potential side effect of DR. All subjects were using DR for mood or behavioral related symptoms, with most diagnosed with schizophrenia, bipolar disorder, or schizoaffective disorder, bipolar type. Additionally, eight subjects had a history of substance abuse.

Seven of the ten subjects were converted on an equal milligram-per-milligram basis, while the other three received a 250 $\mathrm{mg}$ dose increase to $500 \mathrm{mg}$ as at the time of the study only 500 mg ER tablets were available. The mean DR dose at baseline was $2,475 \pm 1,010 \mathrm{mg} /$ day with a slightly higher mean dose of ER observed at study endpoint, 2,550 $\pm 985 \mathrm{mg} /$ day. The study group included six males and four females with an average age of 39.4 years and an average length of mental illness of 21.4 years. Subjects were diagnosed primarily with schizophrenia $(n=4)$, bipolar disorder $(\mathrm{n}=2)$, and schizoaffective disorder $(\mathrm{n}=2)$. Eight subjects had a history of substance abuse.

The primary outcome measure in this study was the 18-item Brief Psychiatric Rating Scale (BPRS), selected to identify any changes in psychiatric, behavioral, or mood related symptoms. The BPRS was completed at baseline and then at Days 7, 14, 21, and 28. The results from this study demonstrated that subjects maintained psychiatric and mood stability. Of particular interest, no significant changes were appreciated in weekly BPRS scores, although numerically the mean scores improved from baseline $(29.10 \pm 6.28)$ to endpoint (26.5 $\pm 7.14, p=0.208)$. No individual BPRS items showed a statistically significant change, however a trend suggested a decrease in somatic complaints $(\mathrm{p}=0.057)$.

Eleven-hour post-dose valproic acid serum concentrations were collected at Days 14 and 28. No statistically significant difference was found in DR baseline serum valproic acid concentrations $(90.5 \pm 29.11 \mu \mathrm{g} / \mathrm{mL})$ and "Day 28" 11-hour post-dose ER valproic acid serum concentrations (95.50 \pm 13.68; $\mathrm{p}=0.493$ ). Additional monitoring parameters included assessment of weight changes, and collection hematologic, renal, hepatic, electrolyte, lipid, and glucose labs at baseline and study endpoint. No significant changes in weight were observed between baseline and study endpoint. Serum chemistry monitoring showed statistically significant decreases in LDL cholesterol and potassium, although the decline in potassium was not clinically significant. There were no significant changes in platelet counts observed during the course of the study. Tolerability and adverse event assessment was as measured by the Systematic Assessment for Treatment Emergent Effects (SAFTEE) at baseline and then Days 7, 14, 21, and 28. SAFTEE results showed statistically significant reductions in complaints of sedation, stomach and abdominal discomfort, and tremor from baseline to study endpoint. This study was limited by a small sample size and the inclusion of only stable patients, thus not allowing the clinical application the ER findings to the acute phase of treatment. Additionally, the study subjects showed a broad variation of Axis I diagnosis, not limited to bipolar disorder. Despite these limitations, this study does provide some level of evidence that ER can be used in place of DR to help maintain psychiatric stability.

A third open-label, six day study was designed to compare the conversion of stable bipolar I or II or schizoaffective subjects $(n=12)$ from the DR to the ER formulation (Centorrino et al 2003). Upon entry into the study, subjects were required to have baseline serum valproic acid levels within the therapeutic range of $50-120 \mu \mathrm{g} / \mathrm{mL}$ and had to have been receiving stable does of medications for at least four weeks prior to study initiation.

Participants were switched to ER with a goal of maintaining stable valproic acid serum concentrations. As the 
ER formulation was only available in the $500 \mathrm{mg}$ tablet dosage form at the time of the study, doses were rounded to the nearest $500 \mathrm{mg} /$ day. Serum valproic acid levels were collected at baseline, day 7 , week 6 , and one week following a medication adjustment. In this cohort of patients, it was observed that ER doses needed to be $20.7 \%$ higher than the previous DR doses to maintain serum valproic acid levels, a finding consistent with package labeling for ER.

Numerous efficacy measurements were evaluated at baseline and weekly thereafter and included the Young Mania Rating Scale (YMRS), the 17-Item Hamilton Depression Rating Scale (HAM-D 17), Clinical Global Impression of severity (CGI-S) and improvement (CGI-I), Global Assessment of Functioning Scale (GAF), and the 17-item Brief Psychiatric Rating Scale (BPRS). The mean baseline YMRS score was $3.00 \pm 3.86$ and at endpoint it increased to $3.42 \pm 2.53$. The baseline mean HAM-D 17 score was $11.2 \pm$ 9.3 and at endpoint the mean improved to $7.67 \pm 6.97$. The mean CGI of severity score at baseline was $2.58 \pm 0.79$ and at endpoint was $2.75 \pm 0.65$. The mean baseline GAF score was $68.3 \pm 6.2$ and at endpoint improved marginally with a value of $69.2 \pm 6.0$. The baseline mean BPRS score was $39.8 \pm 10.2$ and at endpoint was $37.8 \pm 7.82$. None of the observed changes were deemed to be significant in regards to psychiatric stability.

Tolerability was assessed using the UKU Side Effect Rating Scale for adverse effects. The most commonly reported adverse effects at both baseline and endpoint were impaired concentration, fatigue, depression, and decreased salivation. The only statistically significant adverse event that was seen more frequently with the ER dosage form as compared to the DR was an increase in polyuria-polydipsia. All participants elected to continue treatment with the ER dosage formulation at the conclusion of the study. This study was also not without limitations, most notably a small sample size and the inclusion of only stable patients.

Three small studies which have been published as "Letter to the Editors" are useful in reporting conversions from DR to ER dosage formulations in psychiatric outpatients (Longo 2005; Minirth and Veal 2005; Jackson et al 2006). In the first of these studies, a small, 12-week, open-label, pilot trial examined outpatients diagnosed with bipolar I or II disorder or schizoaffective disorder (Longo 2005). The patients described in this study were being treated with the DR formulation, but were reporting associated adverse events. The dose conversion was carried out per package labeling which recommends up to a $20 \%$ dose increase in converting from DR to ER. No additional medication changes were allowed during the 12-week observation period. The primary outcome measures were the Clinical Global Impression Scale (CGI) and the Global Assessment of Functioning scales (GAF).

According to these outcome measures, 9 of 10 patients were considered to exhibit no change or slight improvement in their symptoms, while 5 of 10 reported improvements in adverse events. Baseline psychometric assessment scoring, dosing information, length of prior treatment, and therapeutic drug monitoring parameters were collected, however none of the values were reported. This study possesses several limitations, however it does provide some information regarding practical experience with converting patients.

The second of the "Letter to the Editor" publications described a retrospective chart review that focused on the evaluation of efficacy, tolerability, and impact on adherence when switching patients from DR to ER (Minirth and Veal 2005). Psychiatric patients, including those diagnosed with bipolar disorder types I and II, were included. Participants eligible for enrollment had to have been taking DR for at least three months prior to the switch.

Patients were evaluated using the CGI-S scale on the day of the switch from DR to ER and again during the follow-up visit. Additional secondary assessments which were evaluated at baseline and endpoint included Self-Rating Report of Symptoms and review of clinician's notes regarding patient symptomatology.

The study was conducted at a single study site and included the records of 32 patients. Doses of divalproex sodium DR ranged from 125 to $1000 \mathrm{mg}$ /day and following the milligram-for-milligram switch patients were maintained on 500-2000 mg/day of ER.

While this report suggests clinical improvement, the ability to critically evaluate the study is limited by a lack of data showing baseline and endpoint scores for the outcome measures. Therapeutic drug monitoring, particularly serum valproic acid levels, were not mentioned in the design of the study and were not reported. Adherence, one of the secondary outcome measures, was patient rated and evaluated by a telephone interview conducted by the raters. Statistical analysis was not performed on the data collected.

The third "Letter to the Editor" briefly described the conversion of 52 patients stabilized on DR who were converted on an equal milligram-per-milligram basis to the ER formulation for up to 24 weeks (Jackson et al 2006). Psychometric assessment measures included the HAM-D 21 (21-item scale) and YMRS. Utilizing the statistical method of repeated measures analysis, statistically significant improvement was noted from the time of conversion to study endpoint with 
both the HAM-D 21 and YMRS. No significant changes were identified in therapeutic drug monitoring lab values and overall patients reported improved tolerability of the ER formulation.

The use of ER in the management of psychiatric symptoms has not been limited to bipolar disorder alone. One 4-week, open-label DR to ER conversion study included thirty patients diagnosed with schizophrenia (Citrome, Tremeau et al 2004). To be included in the study, patients had to be on a stable dose (1,000 to 3,000 mg/day) of DR for at least 4 weeks. Patients were converted at a $1: 1 \mathrm{mg}$ ratio $(n=12)$ for DR to ER if the baseline serum concentration of valproate was $\geqslant 85 \mu \mathrm{g} / \mathrm{mL}$ and 1:1.2 $\mathrm{mg}$ ratio $(\mathrm{n}=18)$ for DR to ER if the baseline serum concentration of valproate was $<85 \mu \mathrm{g} / \mathrm{mL}$. Dosing required the use of $500 \mathrm{mg}$ increments due to the lack of availability of the $250 \mathrm{mg}$ tablet at the time of the study. The BPRS was the primary outcome measure with side effects assessed with the UKU Side Effect Rating Scale.

Twenty-seven of 30 patients completed the 4-week study. The baseline mean BPRS total score was $37.9 \pm 9.2(n=30)$ and the mean endpoint BPRS score was 35.7 $\pm 11.2(n=29)$, producing a significant mean reduction of $2.3 \pm 5.4$ points $(\mathrm{p}=0.0322)$. Significant improvement was noted for the $1: 1 \mathrm{mg}$ conversion group $(\mathrm{p}=0.0561)$, but not for the $1: 1.2 \mathrm{mg}$ group $(\mathrm{p}=0.2223)$. Mean UKU scores also showed significant improvement, dropping from a mean of $8.8 \pm 6.7(n=29)$ at baseline to $7.5 \pm 5.8(\mathrm{n}=28)$ at endpoint, though for patients with evaluable baseline and endpoint scores the mean change was a reduction of $2.2 \pm 4.1(\mathrm{n}=27, \mathrm{p}=0.0111)$.

The mean DR dose at study entry was $1,592 \mathrm{mg} \pm 498$ $\mathrm{mg}$ /day which produced a mean baseline trough (12-hours post-dose) valproate concentration of $80.1 \pm 20.4 \mu \mathrm{g} / \mathrm{mL}$. The ER dosing at study endpoint was $1,950 \mathrm{mg} \pm 592 \mathrm{mg} /$ day which produced a mean trough concentration (24-hours post-dose) of $73.1 \pm 24.2 \mu \mathrm{g} / \mathrm{mL}$. The $1: 1 \mathrm{mg}$ conversion group produced trough levels that were significantly lower at endpoint compared to baseline $(\mathrm{p}=0.0006)$, though the difference in baseline and endpoint levels for the 1:1.2 conversion group were not $(\mathrm{p}=0.7102)$.

The conversion of DR to ER was not associated with any reports of psychiatric decompensation. While the BPRS was noted to improve across the group, the small reduction should not be interpreted as being more effective as this study is limited by being open-label, small sample size, short duration, and the actual improvement was only a $6 \%$ reduction in total BPRS score. The improvement of UKU scores are consistent with other reports of improved tolerability associated with the ER formulation.

\section{Conclusion}

Current literature evaluating the use of ER in psychiatric patients with bipolar disorder suggests the ER formulation has advantages over the DR formulation. In contrast to DR, the ER formulation provides a dosage form of divalproex that is pharmacokinetically supported for once-daily dosing. While the studies included in this review were not specifically designed to examine differences in medication compliance rates, a correlation between once daily dosing and medication adherence has been established. Of additional benefit, ER had improved tolerability over DR, likely the result of lower peak plasma concentrations without apparent risk of lost efficacy.

The studies included in this review article are greatly limited when utilizing a strict evidence based medicine review procedure. The studies included are not blinded or controlled, they are limited by small sample sizes, they are of shortduration, and are not powered. There is broad variation in the samples making cross-comparisons unreasonable. From a statistical standpoint, there is potential for a beta error, a declaration of no difference when a difference indeed exists, could result in a study not adequately designed to evaluate for mathematical significance.

Despite these severe limitations, there is value in the information that has been reported in these study findings. These studies provide practical practice information on converting from DR to ER in clinical settings and what can be expected in terms of efficacy, tolerability, and therapeutic drug monitoring. While there is no data indicating that the ER formulation provides any enhanced efficacy over DR there is also no compelling data suggesting there is a risk to using the ER over the DR. formulation. The current treatment guidelines included in this review do not specifically recommend the ER formulation and from an evidence perspective one cannot say there is strong enough evidence to make it a first-line choice over other treatment options. However, given that the molecule is the same (divalproex) and that the primary differences are rate of release and a reduced peak concentration, the ER formulation should be considered a safe alternative to DR, particularly when there is a history or concern of dose related (peak concentration) adverse events or when once a day dosing is preferred in an effort to enhance compliance.

\section{Disclosure}

Dr. Stoner serves on Speaker's Bureaus for Asrta Zereca and Janssen Pharmaceuticals. Dr. Stoner has also received investigator-initiated grant support from Abbott 
Pharmaceuticals, IVAX Pharmaceuticals, and Glaxo SmithKline Pharmaceuticals. Dr. Dahmen has no conflicts of interest.

\section{References}

Abbott Laboratories. January 2006a. Depakote ${ }^{\circledR}$ package insert. North Chicago, IL.

Abbott Laboratories. January 2006b. Depakote ER ${ }^{\circledR}$ package insert. North Chicago, IL.

AstraZeneca. October 2006. Seroquel ${ }^{\circledR}$ package insert. Wilmington, DE.

[APA] American Psychiatric Association. 2000. Diagnostic and statistical manual of mental disorder, Fourth Edition-Text Revision. Washington, DC: American Psychiatric Association.

Bowden CL, Gitlin MJ, Keck PE, et al. 2002. Practice Guideline for the treatment of subjects with bipolar disorder (revision). Am J Psychiatry, 159(April Suppl):1-50.

Bristol-Myers Squibb. October 2006. Abilify ${ }^{\oplus}$ package insert. Princeton, NJ.

Brunello N. 2004. Mood stabilizers: protecting the mood...protecting the brain. Journal of Affective Disorders, 79(Suppl 1):S15-20.

Casey DE, Daniel DG, Wassef AA, et al. 2003. Effect of divalproex combined with olanzapine or risperidone in patients with an acute exacerbation of schizophrenia. Neuropsychopharmacology, 28:182-92.

Centorrino F, Kelleher JP, Berry JM, et al. 2003. Pilot comparison of extended-release and standard preparations of divalproex sodium in patients with bipolar and schizoaffective disorders. Am J Psychiatry, 160:1348-50.

Citrome L, Casey D, Daniel DG, et al. 2004. Adjunctive divalproex and hostility among patients with schizophrenia receiving olanzapine or risperidone. Psychiatric Services, 55:290-4.

Citrome L, Tremeau F, Wynn PS, et al. 2004. A study of the safety, efficacy, and tolerability of switching from the standard delayed release preparation of divalproex sodium to the extended release formulation in patients with schizophrenia. J Clin Psychopharmacol, 24:255-9.

Dutta S, Zhang Y, Selness DS, et al. 2002. Comparison of the bioavailability of unequal doses of divalproex sodium extended-release formulation relative to the delayed-release formulation in healthy volunteers. Epilepsy Research, 49:1-10.

Eli Lilly and Company. Nov 13, 2006. Zyprexa ${ }^{\circledR}$ package insert. Indianapolis, IN

GlaxoSmithKline. Sep 2003. Eskalith ${ }^{\circledast}$ package insert. Research Triangle Park, NC.

GlaxoSmithKline. Sep 2006. Lamictal ${ }^{\circledR}$ package insert. Greenville, NC.

Harwood AJ. 2005. Lithium and bipolar mood disorder: the inositol-depletion hypothesis revisited. Molecular Psychiatry, 10:117-26.

Harwood AJ, Agam G. 2003. Search for a common mechanism of mood stabilizers. Biochemical Pharmacology, 66:179-89.

Hirschfeld RM, Calabrese JR, Weissman MM, et al. 2003. Screening for bipolar disorder in the community. J Clin Psychiatry, 64:53-9.

Hirschfeld RM, Lewis L, Vornik LA. 2003. Perceptions and impact of bipolar disorder: how far have we really come? Results of the National Depressive and Manic-Depressive Association 2000 survey of individuals with bipolar disorder. J Clin Psychiatry, 64:161-74.
Horne RL, Cunanan C. 2003. Safety and efficacy of switching psychiatric patients from a delayed-release to an extended-release formulation of divalproex sodium. J Clin Psychopharmacol, 23:176-81.

Jackson RS, Venkataraman S, Atkins RB, et al. 2006. Efficacy and tolerability of divalproex extended release in psychiatric patients. Annals of Clinical Psychiatry, 18:273-4.

Janssen. Oct 2006. Risperdal ${ }^{\oplus}$ package insert. Titusville, NJ.

Judd LL, Akiskal HS, Schettler PJ, et al. 2002. The long-term natural history of the weekly symptomatic status of bipolar I disorder. Arch Gen Psychiatry, 59:530-7.

Keck PE, Perlis RH, Otto MW, et al. Dec 2004. The expert consensus guideline series: treatment of bipolar disorder 2004. Postgraduate Medicine, 1-116.

Lehman AF, Lieberman JA, Dixon LB, et al. 2004. Practice guideline for the treatment of patients with schizophrenia, second edition. Am $J$ Psych, 161:1-56.

Longo LP. 2005. Extended-release divalproex sodium for patients with side effects from delayed-release divalproex sodium. Am J Psychiatry, 162:1548-9.

Loscher W. 2002. Basic pharmacology of valproate: a review after 35 years of clinical use for the treatment of epilepsy. CNS Drugs, 16:669-94.

McElroy SL. 2004. Diagnosing and treating comorbid (complicated) bipolar disorder. J Clin Psychiatry, 65(Suppl 15):35-44.

Minirth FB, Veal V. 2005. Assessment of patient preference and side effects in patients switched from divalproex sodium delayed release to divalproex sodium extended release. J Clin Psychopharmacol, 25:99-101.

Owens MJ, Nemeroff CB. 2003. Pharmacology of valproate. Psychopharmacology Bulletin, 37(Suppl 2):S17-24.

Pfizer. May 2005. Geodon ${ }^{\circledR}$ package insert. New York, NY.

Salloum IM, Cornelius JR, Daley DC, et al. 2005. Efficacy of valproate maintenance in patients with bipolar disorder and alcoholism. Arch Gen Psychiatry, 62:37-45.

Shaltiel G, Shamir G, Shapiro J. 2004. Valproate decreases inositol biosynthesis. Biological Psychiatry, 56:868-74.

Shire US Inc. Dec 2004. Equetro ${ }^{\circledast}$ package insert. Wayne, PA.

Solvay Pharmaceuticals. Jan 2006. Lithobid ${ }^{\circledR}$ package insert. Marietta, GA.

Stoner SC, Dubisar BM, Lea JW, et al. 2004. Extended-release divalproex sodium for mood stabilization. Pharmacotherapy, 24:1147-53.

Suppes T, Dennehy EB, Hirschfeld RM, et al. 2005. The Texas implementation of medication algorithms: update to the algorithms for treatment of bipolar I disorder. J Clin Psychiatry, 66:870-86.

Taylor MJ, Goodwin GM. 2006. Long-term prophylaxis in bipolar disorder. CNS Drugs, 20:303-10.

Toth M. 2005. The epsilon theory: a novel synthesis of the underlying molecular and electrophysiological mechanisms of primary generalized epilepsy and the possible mechanism of action of valproate. Medical Hypotheses, 64:267-72.

Zarate CA, Tohen M, Narendran R, et al. 1999. The adverse effect profile and efficacy of divalproex sodium compared with valproic acid: a pharmacoepidemiology study. J Clin Psychiatry, 60:232-6. 